\title{
The Lateral Distortional Buckling of I-Plate Girders
}

\author{
Hanan Gamal, M. El-Boghdadi, M. F. Hassanein and A. M. EL Hadidy
}

\begin{abstract}
This paper presents a numerical study for lateral distortional buckling of I-plate girders (LDBIPGs) by using the general-purpose finite element package ABAQUS (version 6.13) software. 3-D finite element (FE) models for simply supported IPGs subjected to two cases of loading are built. The first case of loading was uniform end moment that was introduced by a couple of forces applied at the top and bottom flanges of the IPGs. The second case of loading was a concentrated load at the shear center in the mid-span. First, shell finite element models are validated by comparing the $\mathrm{FE}$ critical bending moment $\left(M_{c r, F E}\right)$ by the critical bending moment in EC3 code $\left(M_{c r, o, L T B}\right)$. The results indicate that the $M_{c r, F E}$ was in good agreement with $M_{c r, o, L T B}$. Secondly, a preliminary analysis is conducted to the relative girder slenderness $(\lambda)$ where the LDB too place. Finally, a parametric study is carried out on simply supported IPGs regarding to the span length, the flange cross-section dimensions and the thickness of the web. The results showed that increasing the length of girders decreases $M_{c r F E}$ and increase in the bending coefficient factor $\left(C_{b}\right)$. Also, decreasing in the web plate slenderness ratio $\left(h_{w} / t_{w}\right)$ works on increasing in $M_{c r . F E}$ values and $C_{b}$. The results also showed that the increasing in the thickness of flange increases $M_{c r . F E}$ and increase the value of $C_{b}$ with small value. As a result of parametric study, the mean value and standard deviation of $C_{b}$ for LDB mode are 1.16 and 0.08 respectively for $\lambda$ limits (90:130). For $\lambda$ limits (131:175), the mean value and standard deviation of $C_{b}$ are 1.27 and 0.03 respectively. As for $\lambda$ limits (176:221), the mean value and standard deviation of $C_{b}$ are 1.32 and 0.02 respectively.
\end{abstract}

Keywords: Lateral distortional buckling - uniform end moment - bending coefficient factor.

\section{INTRODUCTION}

It is well known that I-steel plate girders (IPGs), obtained by web plate elements and flanges, when these girders are loaded in its principle plane, it may occur buckling out of plane if it does not have sufficient lateral stiffness [1-6]. These girders can buckle by lateral deflection and twisting of the crosssection. This phenomenon called by lateral torsional buckling (LTB) and this type of buckling involve lateral deflection and twist in upper flange liked in the lower flange as shown in Fig. 1-a. There is another type of buckling is known as local buckling (LB) in which compression elements (compression flanges or webs) can buckle locally over a short length of the member with local changes in the shape of cross section as shown in Fig. 1-b. It is important to know that two modes of buckling (lateral torsional buckling and local buckling) may interact to consist anther mode of buckling called by lateral distortional buckling (LDB) as can be seen in Fig. 1-c.

In intermediate-length IPGs with slender webs and stocky flanges the overall lateral deformation of the IPGs may be accompanied by web distortions [7-10]. This mode of buckling also placed on IPGs, which have a large flexural rigidity in their loaded plane and a small flexural rigidity in the other plane. In this mode, the flange can deflect laterally with rotation in upper flange non-in the lower flange and the web will be distorted. This buckling mode reduced torsional rigidity of the section and this obvious in plate girders with slender and un-stiffened webs than in stocky webs [9-11].

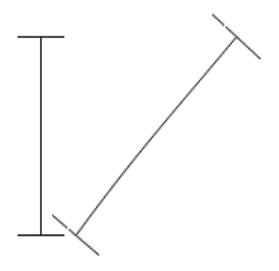

(a) LTB

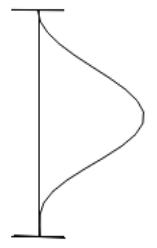

(b) LB

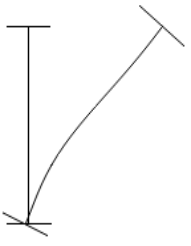

(C) LDB
Fig.1. Different buckling modes of steel IPGs

Many studies have been performed separately on LB and LTB, and codes of practice for the design of structural steelwork contain the relevant clauses. LDB is less well known and has long been ignored in design specification $[10,11]$. Work in the last years has added much to our understanding of this type of buckling and after many years of relative neglect, LDB has recently been the subject of a good deal [10-13].

The research conducted herein on the behavior of the IPGs were developed using the general-purpose FE package ABAQUS [14] based upon the availability of trusted FE models in the literature.

In 2013, Hassanein and Silvestre investigated stainless steel IPGs numerically [15]. Moreover, the flexural strength of hollow tubular flange plate girder was studied by Hassanein and Kharoob [16]. The moment-gradient factor $C_{b}$ was found to influence by the girder geometry and slenderness for the case of HTFPGs with slender stiffened webs [17].On the other hand, an experimental and analytical research investigated the structural characteristics of lean duplex stainless steel Isections by Saliba and Gardner [18]. Tadeh Zirakian [19], focused on LDB of doubly symmetric I-shaped members with slender web. Kalkan and Alper [20] studied the effect of web distortion in a lateral distortional buckling mode on the buckling moments of doubly symmetric steel IPGs analytically and numerically.

In 2018, Elkawas et al, studied LTB strength and behavior of high-strength steel corrugated web girders [21]. In 2019, Chen et al studied the mechanical properties and crosssectional behavior of additively manufactured high-strength steel tubular sections [22].

In this research, LDB was studied on IPGs subjected to two type of loading. The aim of this study is getting $M_{c r, F E}$ and the value of $C_{b}$ to the IPGs that have the buckling mode is LDB.

\section{LDB OF CARBON STEEL IPGS}

It was known also that the elastic LTB moment of IPGs under uniform bending was obtained from the following 
equation [15],

$M_{\text {cr.o.LTB }}=\frac{\pi}{k L} \sqrt{E I_{y} G J\left(1+\frac{\pi^{2}}{\left(k_{w} L\right)^{2}} \frac{E c_{w}}{G J}\right)}$

Where $\mathrm{L}$ is the unbraced length, $\mathrm{k}$ is the buckling coefficient regarding the out-of-plane flexural rotations at the supports, $k_{w}$ is the buckling coefficient regarding the restrained warping at the supports, $E I_{y}$ is the minor axis flexural rigidity, GJ is the torsional rigidity, and $E c_{w}$ is the warping rigidity. These are given by,

$G J=\frac{E}{6(1+v)}\left(2 b_{f} t_{f}^{3}+h_{w} t_{w}^{3}\right.$

$E c_{w}=E \frac{t_{f} b_{f}{ }^{3}\left(h_{w}+t_{f}\right)^{2}}{24}$

where $\mathrm{E}$ is the Young's modulus, $\mathrm{G}$ is the shear modulus, $v$ is the Poisson's ratio, $b_{f}$ is the flange width, $t_{f}$ is flange thickness, $h_{w}$ is the web height and $t_{w}$ is the web thickness of the IPGs.

However, past research on carbon steel IPGs yielded a high level of understanding their LDB behavior. Accordingly, Pi and Trahair [23] showed that the elastic LDB moment ( $M_{c r, o, L D B}$ ) might be obtained from (4). Their main idea suggests that a reduction in the warping stiffness due to web distortions should be taken into account in addition to a reduction in the torsional stiffness when calculating the LDB moment of an IPG with stocky flanges.

$$
\begin{aligned}
& M_{\text {cr.o.LDB }}=\frac{\pi}{k L} \sqrt{E I_{y} G J_{e}\left(1+\frac{\pi^{2}}{\left(k_{w} L\right)^{2}} \frac{E c_{w e}}{G J_{e}}\right)} \\
& G J_{e}=\frac{\left(2 G J_{f}\right)\left(\frac{12 D_{w} L^{2}}{\pi^{2} h_{w}}\right)}{\left(2 G J_{f}\right)+\left(\frac{12 D_{w} L^{2}}{\pi^{2} h_{w}}\right)} \quad \text { with } D_{W}=\frac{E t_{w}{ }^{3}}{12\left(1-v^{2}\right)} \\
& E c_{w e}=\frac{E c_{w}}{1+r f_{w}{ }^{3}\left(\frac{h_{w}}{12 l_{b}}\right)\left(1+\frac{b_{f}}{h_{w}}\right)}
\end{aligned}
$$

where $\mathrm{G} J_{f}$ is the torsional rigidity of the flange and $\mathrm{r} f_{w}$ is the smaller of $t_{f} / t_{w}$ and 2. The reduced torsional $\left(\mathrm{G} J_{e}\right)$ and warping $\left(\mathrm{E} c_{w e}\right)$ rigidities, as given above, were shown to approach the torsional $(\mathrm{GJ})$ and warping $\left(E c_{w}\right)$ rigidities as the flange stockiness and the web slenderness of IPG.

Current design codes [24, 25, 26] account for the influence of the moment gradient on the IPGs through a modification coefficient factor that is referred to as the moment gradient coefficient $\left(C_{b}\right)$. This coefficient relates the critical buckling moment $M_{c r}$ for a girder subjected to concentrated load to the corresponding critical buckling moment $M_{o, c r}$ of the same girder under a uniform end moment, as given by (7).

This coefficient relates the critical buckling moment $M_{c r}$ for IPG subjected to specific transverse load to the corresponding critical buckling moment $M_{o, c r}$ of the same IPG under a uniform moment, as given by (7). The value of this nondimensional factor is always greater than 1.0 for a varying bending moment diagram.

$$
C_{b}=\frac{M_{c r}}{M_{o, c r}}
$$

\section{FINITE ELEMENT MODELLING}

\section{A. Current FE model}

Using ABAQUS [14], 3-D FE models for simply supported IPGs subjected to two load cases (uniform end moment and mid-span concentrated load at shear center). The buckling modes are estimated through the Eigenvalue analysis. This is a linear analysis performed using the (*BUCKLE) procedure available in the ABAQUS library with the load applied within the step. The first buckling mode occurred in the eigenvalue analysis was used to estimate the FE critical bending moment $\left(M_{c r, F E}\right)$. The following sections includes considerations in choosing the mesh, material modeling, and modeling of the boundary conditions, load application and verification of the model.

\section{B. Element type, mesh and material properties}

The four-node thin shell elements with reduced integration S4R was used in the current FE model, which is the same element used in the FE model of [15]. S4R has six degrees of freedom per node, provides high accuracy for most of thinwalled girder applications and allows for transverse deformation. The FE also accounts for finite strain and is suitable for large strain analysis. Simpson rule with five integration points was used through the included element thickness. As mentioned in [16], the researchers were found that a mesh size of $50 \mathrm{~mm}$ is appropriate for the purpose of this work. The young's modulus $E_{o}=200 \mathrm{GPa}$, Poisson's ratio $v=$ 0.3 were considered.

\section{Load application and boundary conditions}

Two types of load application was applied on the FE model, as shown in Fig. 2. The first one was a uniform bending moment about the major axis of the IPGs over the unbraced lengths. To avoid any undesirable localized web deformations and stress on centration, the end moment loading was simulated with couple of forces in the form of uniform loading applied at the top and bottom flanges of the IPGs. In this loading type, the top flange is subjected to compressive longitudinal forces, while the bottom flange is subjected to tensile forces opposing the compressive ones. The second load application was a concentrated load at shear center of IPGs in mid-span. The boundary conditions are taken herein following the work conducted numerically in [27]. However, simply supported boundary conditions are applied to end sections. As shown in Fig. 2, at each end section, the twist rotation about zaxis of all nodes of the section is restrained $\left(\emptyset_{z}=0: 0\right)$. The lateral displacement in $\mathrm{x}$-axis of all nodes on the $\mathrm{y}$-axis (at $\mathrm{x}=$ $0: 0)$ is restrained $\left(U_{x}=0: 0\right)$. The vertical displacement of the center of the web is restrained $\left(U_{y}=0: 0\right)$, while the longitudinal displacement in z-axis of a center point at the lower flange is restrained $\left(U_{z}=0: 0\right)$. It should be noted that current boundary conditions and load application provide the most conservative loading distribution. 


\section{Stiffeners arrangement}

Using transverse stiffeners along the girder length influence the failure mode in the IPGs. In addition, Akay et al. [28] found that the lateral distortional buckling of IPGs may be enhanced by using transverse stiffeners to prevent distortion by coupling the rotational degree of freedom of the top and bottom flanges. White and Jung [29] found that when the limit on the maximum stiffener spacing of $a / h_{w}=3$ is satisfied throughout the unbraced length of IPGs, the web distortion effects will in general be reduced; where $a$ is the web panel width of the IPGs [30]. This mean, using the previous stiffeners spacing leading to LTB mode.

\section{VERIFICATION OF FE MODEL}

A verification test has been carried out on the six models of IPGs with different dimensions, as given in Table (1). The maximum stiffener spacing of $a / h_{w}<3.0$ is considered to prevent the web distortional. Two types of load application was applied on the models as discussed previously. The girders were subjected to uniform bending moment about the major axis of the IPGs over the unbraced lengths. However, the same girders were subjected to concentrated load in mid-span at shear center. The critical bending moment due to uniform end moment $\left(M_{c r, F E}\right)$ and the critical bending moment due to concentrated load $\left(M_{C r, F E, c}\right)$ were calculated from FE models. Then, the values of $M_{c r, F E}$ were compared with the critical bending moment $\left(M_{O, c r}\right)$ given by (1). The results showed that $M_{c r, F E}$ was in good agreement with $M_{o, c r}$ as shown in Table 2. It can be seen that the mean value and standard deviation of $M_{c r, F E} / M_{o, c r}$ are 0.99 and 0.005 respectively.

Moreover, the values of the bending coefficient factor $\left(C_{b}\right)$ for models were calculated from (7) as shown in Table 2 . The results showed that the average of $C_{b}$ was 1.35 which is the same as recommended by [26].

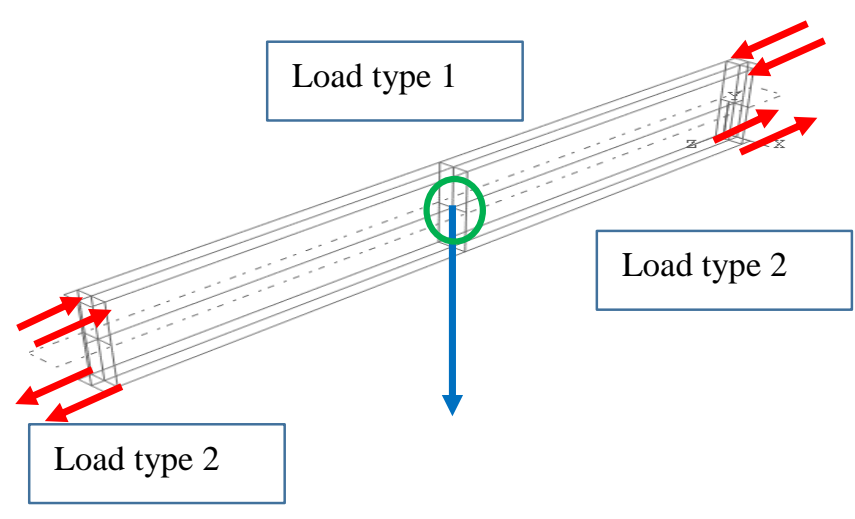

Figure 2. Load application and boundary conditions of the FE model

TABLE 1

GEOMETRICAL PROPERTIES OF IPGS

\begin{tabular}{|c|c|c|c|c|c|}
\hline Models & $\mathrm{L}[\mathrm{m}]$ & $b_{f}[\mathrm{~mm}]$ & $t_{f}[\mathrm{~mm}]$ & $t_{w}[\mathrm{~mm}]$ & $h_{w}[\mathrm{~mm}]$ \\
\hline 1 & 9 & 250 & 30 & 10 & 1140 \\
\hline 2 & 11 & 350 & 30 & 10 & 890 \\
\hline 3 & 1 & 300 & 30 & 10 & 1000 \\
\hline 4 & 15 & 300 & 30 & 10 & 1250 \\
\hline 5 & 17 & 250 & 30 & 10 & 1140 \\
\hline 6 & 19 & 250 & 30 & 10 & 1140 \\
\hline
\end{tabular}

TABLE 2

$M_{c r, F E, c}, M_{c r, F E}, M_{o, c r}$ AND $C_{b}$ VALUES.

\begin{tabular}{|c|c|c|c|c|c|}
\hline Models & $\begin{array}{c}M_{c r, F E, c} \\
{[K N . m]}\end{array}$ & $\begin{array}{c}M_{c r, F E} \\
{[K N . m]}\end{array}$ & $\begin{array}{c}M_{o, c r} \\
{[K N . m]}\end{array}$ & $M_{c r, F E} / M_{o, c r}$ & $C_{b}$ \\
\hline 1 & 1749.3 & 1336.4 & 1352.87 & 0.99 & 1.34 \\
\hline 2 & 2724.8 & 2034.2 & 2008.05 & 1.01 & 1.34 \\
\hline 3 & 1511.25 & 1122.4 & 1130.75 & 0.99 & 1.35 \\
\hline 4 & 1365.8 & 1014.9 & 1025.15 & 0.99 & 1.35 \\
\hline 5 & 712.9 & 526.5 & 536.19 & 0.98 & 1.35 \\
\hline 6 & 614 & 453.9 & 465 & 0.98 & 1.35 \\
\hline & & & Average & 0.99 & 1.35 \\
\hline & & & STDEV & 0.01 & 0.01 \\
\hline
\end{tabular}

\section{PRELIMINARY ANALYSIS}

The main purpose of this research is to study the IPGs failed by LDB. So, a preliminary analysis was developed using ABAQUS program [14] to estimate the limits which LDB occurred. A series of elastic buckling analysis is carried out on 12 groups. The classification of the flanges in the IPGs in the current analysis were compact and non-compact flanges while the web plate was slender. The limits of compact and noncompact flanges in Euro code [25], are shown in the following equations.

$$
c / t \leq 10 \varepsilon \quad \text { for compact flanges }
$$

Where: $t=t_{f}$

$$
\begin{aligned}
& c=\left(b_{f}-t_{w}\right) / 2 \\
& \text { And } \varepsilon=\sqrt{235 / f_{y}}
\end{aligned}
$$

In addition, the limits of non-compact section for flange was:

$$
c / t \leq 14 \varepsilon . \quad \text { for non-compact flanges }
$$

As can be seen in Fig. $3, h_{w}$ represent web depth, $t_{w}$ denotes the web thickness, $b_{f}$ (flange width) and $t_{f}$ (flange thickness). There are two compact flanges and two non-compact flanges were used in the study. The thickness of compact flanges were $25 \mathrm{~mm}$ and $30 \mathrm{~mm}$. Moreover, the thickness of non-compact flanges were $18 \mathrm{~mm}$ and $20 \mathrm{~mm}$. The flange width $\left(b_{f}\right)$ and the web height $\left(h_{w}\right)$ of IPGs were constant which equal $250 \mathrm{~mm}$ and $1000 \mathrm{~mm}$, respectively The web plate slenderness is characterized by web height to web thickness $\left(h_{w} / t_{w}\right)$ values that assumes $166.667,125$ and 100 for web thickness 6,8 and $10 \mathrm{~mm}$ respectively. Each cross section was modeled with 8 different spans $(4,6,8,10,12,14,16,20 \mathrm{~m})$. Table 3 , explained the dimension of sections $\left(t_{f}\right.$ and $\left.t_{w}\right)$ and flange classification where $b_{f}$ and $h_{w}$ are constant as mentioned previous.

Fig. 4 showed the relation between relative girder slenderness $(\lambda)$ and critical bending moment according to uniform end moment $\left(M_{c r, F E}\right)$ for all groups. Where $\lambda=L_{b} / r_{y}$, $L_{b}$ is the laterally unbraced length and $r_{y}$ is the radius of gyration of the compression flange where $r_{y}=\sqrt{I_{y} / A}$ According to [29] and [30], the purpose of using such 
stiffeners in the IPGs was to prevent the occurrence of the local web crippling. Therefore, we should using stiffeners at supports and in mid-span and this leading to LDB mode. The aim of this study, getting the values of $\lambda_{1}$ and $\lambda_{2}$ as shown in fig. (4). When $\lambda \leq \lambda_{1}$, the buckling mode is LB, $\lambda_{1} \leq \lambda \leq \lambda_{2}$, the buckling mode is LDB and $\lambda \geq \lambda_{2}$, the buckling mode is LTB. As shown in fig. 4, we noticed that, the minimum value of $\lambda_{1}$ which its buckling mode was LDB is 90 and the maximum value of $\lambda_{2}$ is 221 . So, when $\lambda$ between 90 and 221 , the buckling mode was LDB. When $\lambda \leq 90$, the buckling mode was LB. When $\lambda \geq 221$, the buckling mode was LTB. The relative girder slenderness for LDB mode assumes 90 to 221 for unbraced length between $6 \mathrm{~m}$ to $14 \mathrm{~m}$ respectively in this study.

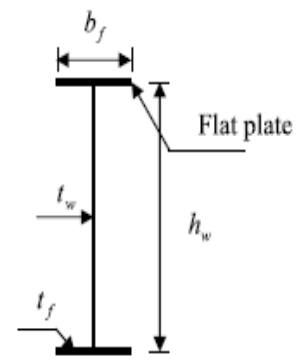

Figure 3. I-section plate girder.

TABLE 3 .

THE DIMENSION OF DIFFERENT CROSS SECTION

\begin{tabular}{|c|c|c|c|}
\hline Groups & $\begin{array}{c}t_{f} \\
{[\mathrm{~mm}]}\end{array}$ & $\begin{array}{c}t_{w} \\
{[\mathrm{~mm}]}\end{array}$ & Flange classification \\
\hline G1 & 18 & 6 & Non-compact \\
\hline G2 & 18 & 8 & Non-compact \\
\hline G3 & 18 & 10 & Non-compact \\
\hline G4 & 20 & 6 & Non-compact \\
\hline G5 & 20 & 8 & Non-compact \\
\hline G6 & 20 & 10 & Non-compact \\
\hline G7 & 25 & 6 & Compact \\
\hline G8 & 25 & 8 & Compact \\
\hline G9 & 25 & 10 & Compact \\
\hline G10 & 30 & 6 & Compact \\
\hline G11 & 30 & 8 & Compact \\
\hline G12 & 30 & 10 & Compact \\
\hline
\end{tabular}

\section{PARAMETRIC STUDY}

A parametric study was developed using ABAQUS program [14] to simulate the behavior of IPGs. The study performed using 72 IPGs where the girders divided into 36 non-compact IPGs sections and 36 compact IPGs sections. The parameters covered herein are based upon the EC3 [25] recommendations. Parametric studies for IPGs are carefully designed based on three parameters: the unbraced length $(\mathrm{L})$, the web plate thickness $\left(t_{w}\right)$ and the flange thickness $\left(t_{f}\right)$. The parameters are included the unbraced length $(\mathrm{L})$ which its buckling mode was LDB assumes five values $(6,8,10,12,14 \mathrm{~m})$ according to preliminary analysis.

\section{RESULTS}

Table 5 and Table 6 show the results of the parametric study. It is clear that from Table 5 and 6 , the value of $M_{c r, F E}$ was smaller than value of $M_{C r, F E, c}$ due to the uniform end moment loading case is worst loading case. Consequently, It is necessary account for the influence of the moment gradient on the IPGs through a modification coefficient factor that is referred to as the moment gradient coefficient $\left(C_{b}\right)$ as in (7). Fig. 5-a and Fig. 5-b demonstrates the variation of the $C_{b}$ coefficient against the length of girders for the simply supported IPGs subjected to mid-span concentrated loads

As can be seen, Fig. 5-a represent non-compact section, whereas $t_{f}=20 \mathrm{~mm}$ and Fig. 5-b represent compact section, whereas $t_{f}=25 \mathrm{~mm}$. This trend shows that the length of girders values assumes $(6,8 \mathrm{~m}, 10 \mathrm{~m}, 12 \mathrm{~m}, 14 \mathrm{~m})$ and the $C_{b}$ coefficient has its maximum value for longer spans that are characterized by lower lengths. A reduction in the $C_{b}$ value is demonstrate for IPGs having shorter spans. With the increase in unbraced length and thickness of web, its $C_{b}$ value is close to 1.35 and the type of failure mode is LTB as shown in Fig. 5-a and Fig. 5 -b. This case can be noticed that for length $14 \mathrm{~m}$ at $\left(t_{w}=10 \mathrm{~m}\right)$.

It can be observed that the path of the moment coefficient factor-unbraced length are nearly linear and coincident as the IPGs have lengths ( $8 \mathrm{~m}$ to $14 \mathrm{~m}$ ). As it can be seen from Fig. 5 -a and Fig. 5-b, these girders fail by LDB. In shorter lengths, the girders fail by LB with decreasing in the web plate thickness as length $6 \mathrm{~m}$ at $t_{w}=6 \mathrm{~mm}$. It is clear that the variation of flange thickness $\left(t_{f}\right)$ does not significantly affect that $C_{b}$ value from $6 \mathrm{~m}$ to $14 \mathrm{~m}$ as evident in Fig. 5-a,b and Table 4. Table 6 explained at length $6 \mathrm{~m}$ are affected by the flange thickness increasing as it decreases.

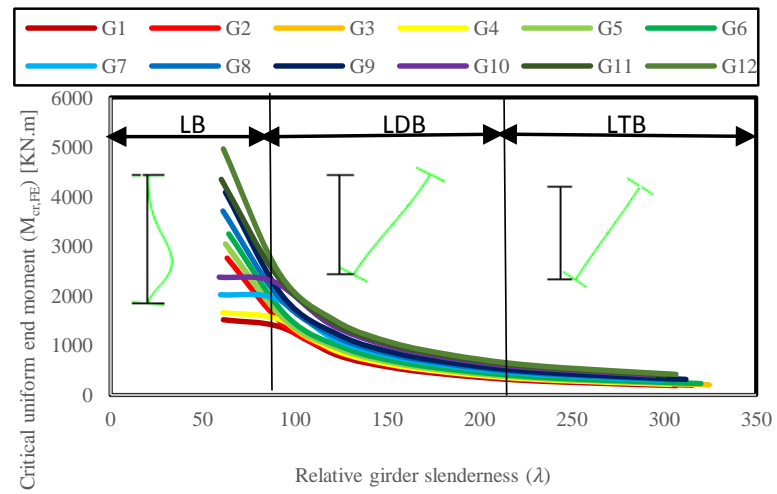

Figure 4. The relation between relative girder slenderness and $M_{c r, F E}$ for all groups.

(a)

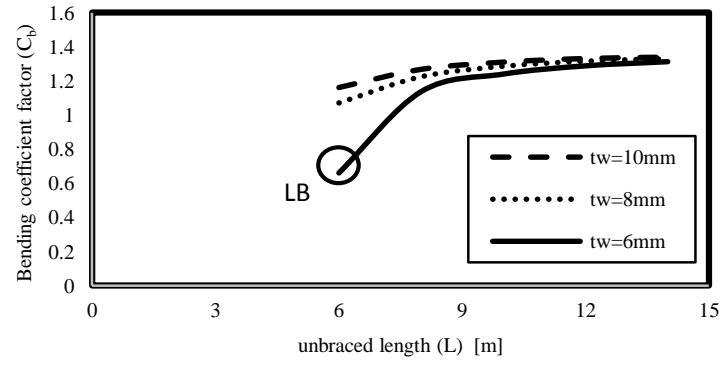


(b)

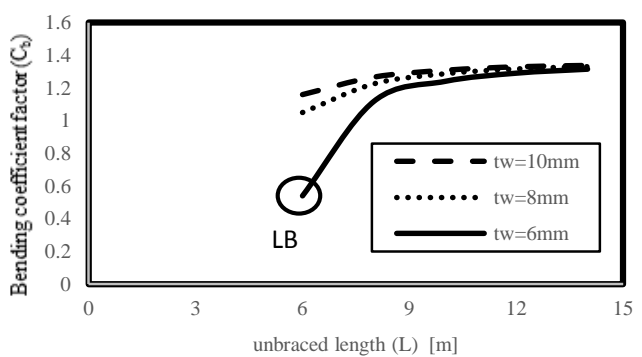

Figure 5. The effect of unbraced length and on $C_{b}$; (a) $t_{f}=20 \mathrm{~mm}$, (b) $t_{f}=25 \mathrm{~mm}$.

As explained earlier, Table (4) explained the values of the bending coefficient factor $\left(C_{b}\right)$ to specimens, which had $h_{w} / t_{w}=125$. It is clear that from Table (4), the $C_{b}$ values for length $(6,8,10,12,14 \mathrm{~m})$ were constant by changing the thickness of flange in lengths from $8 \mathrm{~m}$ to $14 \mathrm{~m}$ and this means, the increasing in flange thickness does not effect on $C_{b}$ values with a clear effect.

TABLE 4

$C_{b}$ VALUES FOR SPECIMENS, WHICH HAD $h_{w} / t_{w}=125$

\begin{tabular}{|c|c|c|c|c|c|c|}
\hline \multirow[b]{2}{*}{ Section type } & & \multirow[b]{2}{*}{6} & \multirow[b]{2}{*}{8} & \multirow[b]{2}{*}{10} & \multirow[b]{2}{*}{12} & \multirow[b]{2}{*}{14} \\
\hline & & & & & & \\
\hline \multirow{2}{*}{$\begin{array}{c}\text { Non } \\
\text { compact }\end{array}$} & 18 & 1.07 & 1.22 & 1.28 & 1.32 & 1.33 \\
\hline & 20 & 1.07 & 1.22 & 1.28 & 1.32 & 1.33 \\
\hline \multirow{2}{*}{ Compact } & 25 & 1.06 & 1.22 & 1.29 & 1.32 & 1.33 \\
\hline & 30 & 1.01 & 1.22 & 1.29 & 1.32 & 1.33 \\
\hline
\end{tabular}

\section{MODE OF FAILURE}

As a result of the preliminary analysis, the failure mode for most specimens which have lengths from $6 \mathrm{~m}$ to $14 \mathrm{~m}$ were LDB. Except few of these specimens failed LB and LTB as shown in table (5) and (6). Fig. 6 explain the relation between the web plate slenderness ratio $\left(h_{w} / t_{w}\right)$ and bending moment coefficient factor $\left(C_{b}\right)$. As shown in Fig. 6 , the path of lengths $(10,12,14 \mathrm{~m})$ is linear. These girders fail by LDB. At lengths $(6,8 \mathrm{~m})$, the value of $\left(C_{b}<1\right)$ and this is refer to the buckling mode is LB. this case occurs in shorter lengths and when the web plate slenderness ratio increases as obvious in Fig. 6.

\subsection{EFFECT OF LENGTH}

\section{A. Non-compact section}

The effect of the unbraced length could be examined by the analysis of the IPGs with non-compact flanges as shown in Table 5. The thickness of flange in these girders was maintained, which equal $18 \mathrm{~mm}$. While, the main variable in these girders was the unbraced length, which assumes $6 \mathrm{~m}, 8 \mathrm{~m}$, $10 \mathrm{~m}, 12 \mathrm{~m}$, and $14 \mathrm{~m}$. The web plate slenderness assumes 166.667, 125 and 100 for web thickness 6,8 and $10 \mathrm{~mm}$ respectively. However, the results indicated that increasing the length of girders decreases $M_{c r . F E}$ and $M_{c r . F E, c}$ as shown in Fig. 7-a which represent the relation between unbraced length in horizontal axis and $M_{c r . F E}$ in vertical axis and Fig. 7-b which represent the relation between unbraced length and $M_{c r . F E, c}$. As shown in Fig. 7-a and Fig. 7-b explained the decrease in $\left(h_{w} / t_{w}\right)$ leads to increase in $M_{c r . F E}$ and $M_{c r . F E, c}$ with small value. As shown in Fig. 7-a, In three cases of web thickness, the path of the moment-unbraced length curves are coincident that's where most of the girders fail by LDB. For Fig. 7-b, the paths of three curves are nearly coincident except at a length of $6 \mathrm{~m}$ where it is buckling mode was LB.

\section{B. Compact section}

By analysis of compact girders which had flange thickness equal $30 \mathrm{~mm}$ as shown in Table 6 , where the length only was variable. It's found that, the $M_{c r . F E}$ and $M_{c r . F E, c}$ values increased due to increase in thickness of flange. Also, the increasing in length leading to decreasing in both $M_{c r . F E}$ and $M_{c r . F E, c}$ with the same amount of shortfall on the previous girders as shown in Fig. 8-a and Fig. 8-b respectively. From Fig. 8-a, all curves take the same path and be close to each other where it is buckling mode is LDB. Fig. 8-b, the path of girders have $6 \mathrm{~m}$ and $8 \mathrm{~m}$ was differ from rest of girders due to its buckling mode was LB. As previously mentioned, with decreasing in the unbraced length and the web thickness and increasing in the flange thickness leads to LB mode.

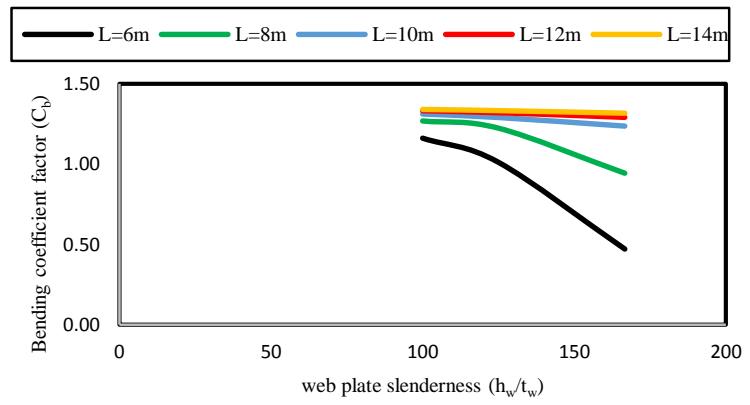

Figure 6. Values of $C_{b}$ for girders that flange thickness $30 \mathrm{~mm}$.

(a)

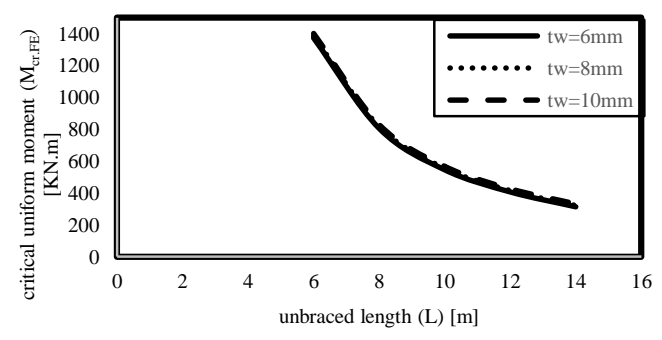

(b)

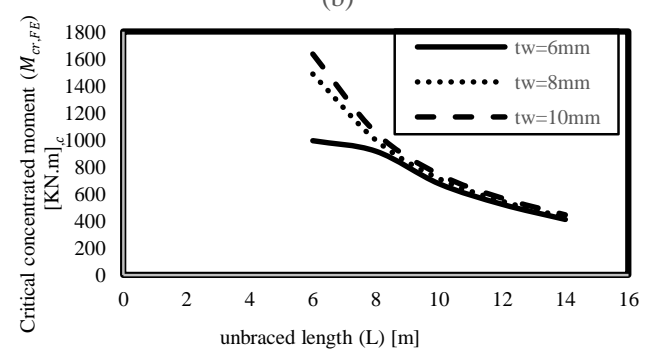

Figure 7. Effect of the unbraced length on $M_{c r, F E}$ and $M_{c r, F E, c}$. 
TABLE 5

THE GEOMETRY OF NON-COMPACT SECTION.

\begin{tabular}{|c|c|c|c|c|c|c|c|c|}
\hline Specimens & $t_{f}[\mathrm{~mm}]$ & $t_{w}[\mathrm{~mm}]$ & {$\left[h_{w} / t_{w}\right]$} & $\mathrm{L}[\mathrm{m}]$ & $\begin{array}{l}M_{c r, F E, c} \\
{[K N . m]}\end{array}$ & $\begin{array}{c}M_{c r, F E} \\
{[K N . m]}\end{array}$ & $C_{b}$ & Buckling mode \\
\hline 1 & 18 & 6 & 166.67 & 6 & 993.87 & 1371.51 & 0.72 & LB \\
\hline 2 & 18 & 6 & 166.67 & 8 & 915.94 & 805.08 & 1.14 & LDB \\
\hline 3 & 18 & 6 & 166.67 & 10 & 675.5 & 545.88 & 1.24 & LDB \\
\hline 4 & 18 & 6 & 166.67 & 12 & 523.47 & 407.16 & 1.29 & LDB \\
\hline 5 & 18 & 6 & 166.67 & 14 & 411.53 & 314.07 & 1.31 & LDB \\
\hline 6 & 18 & 8 & 125 & 6 & 1487.85 & 1385.28 & 1.07 & LDB \\
\hline 7 & 18 & 8 & 125 & 8 & 997.86 & 815.76 & 1.22 & LDB \\
\hline 8 & 18 & 8 & 125 & 10 & 713.025 & 555.03 & 1.28 & LDB \\
\hline 9 & 18 & 8 & 125 & 12 & 546.12 & 415.2 & 1.32 & LDB \\
\hline 10 & 18 & 8 & 125 & 14 & 427 & 321.21 & 1.33 & LDB \\
\hline 11 & 18 & 10 & 100 & 6 & 1634.4 & 1402.47 & 1.17 & LDB \\
\hline 12 & 18 & 10 & 100 & 8 & 1051.48 & 829.65 & 1.27 & LDB \\
\hline 13 & 18 & 10 & 100 & 10 & 742.85 & 567.15 & 1.31 & LDB \\
\hline 14 & 18 & 10 & 100 & 12 & 567 & 426.06 & 1.33 & LDB \\
\hline 15 & 18 & 10 & 100 & 14 & 443.24 & 331.08 & 1.34 & LTB \\
\hline 16 & 20 & 6 & 166.67 & 6 & 1016.13 & 1531.98 & 0.66 & LB \\
\hline 17 & 20 & 6 & 166.67 & 8 & 1025.84 & 903.15 & 1.14 & LDB \\
\hline 18 & 20 & 6 & 166.67 & 10 & 762.7 & 615.69 & 1.24 & LDB \\
\hline 19 & 20 & 6 & 166.67 & 12 & 594.3 & 461.79 & 1.29 & LDB \\
\hline 20 & 20 & 6 & 166.67 & 14 & 469.945 & 358.38 & 1.31 & LDB \\
\hline 21 & 20 & 8 & 125 & 6 & 1655.85 & 1546.2 & 1.07 & LDB \\
\hline 22 & 20 & 8 & 125 & 8 & 1119.4 & 914.7 & 1.22 & LDB \\
\hline 23 & 20 & 8 & 125 & 10 & 803.95 & 625.74 & 1.28 & LDB \\
\hline 24 & 20 & 8 & 125 & 12 & 618.96 & 470.61 & 1.32 & LDB \\
\hline 25 & 20 & 8 & 125 & 14 & 486.71 & 366.15 & 1.33 & LDB \\
\hline 26 & 20 & 10 & 100 & 6 & 1821 & 1564.14 & 1.16 & LDB \\
\hline 27 & 20 & 10 & 100 & 8 & 1177 & 929.34 & 1.27 & LDB \\
\hline 28 & 20 & 10 & 100 & 10 & 835.625 & 638.37 & 1.31 & LDB \\
\hline 29 & 20 & 10 & 100 & 12 & 640.86 & 481.8 & 1.33 & LDB \\
\hline 30 & 20 & 10 & 100 & 14 & 503.51 & 376.17 & 1.34 & LTB \\
\hline
\end{tabular}

(a)

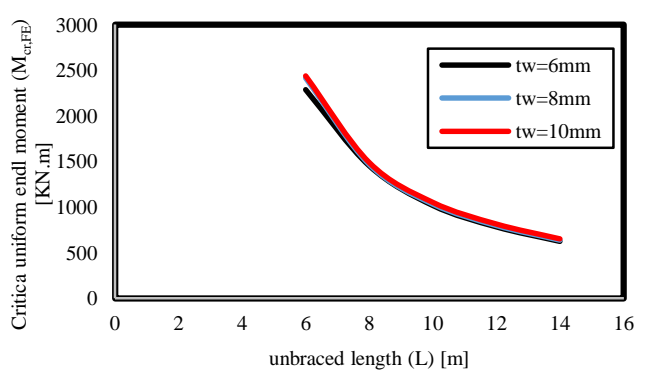

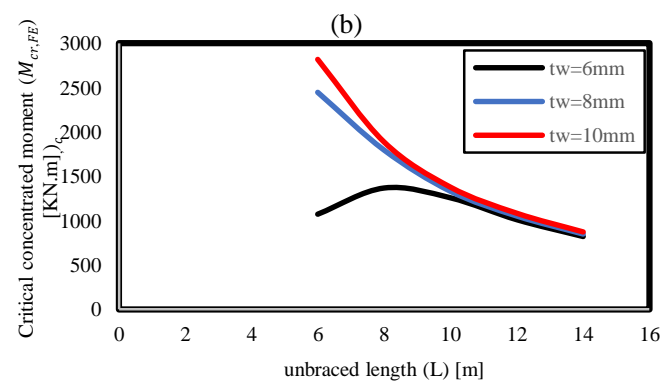

Figure 8. Effect of the unbraced length on (a) $M_{c r, F E}$ and (b) $M_{c r, F E, c}$ 
Table (6)

THE GEOMETRY OF COMPACT SECTIONS

\begin{tabular}{|c|c|c|c|c|c|c|c|c|}
\hline Specimens & $t_{f}[\mathrm{~mm}]$ & $t_{w}[\mathrm{~mm}]$ & {$\left[h_{w} / t_{w}\right]$} & $\mathrm{L}[\mathrm{m}]$ & $\begin{array}{l}M_{c r, F E, c} \\
{[K N . m]}\end{array}$ & $\begin{array}{c}M_{c r, F E} \\
{[K N . m]}\end{array}$ & $C_{b}$ & Failure mode \\
\hline 31 & 25 & 6 & 166.67 & 6 & 1052.1 & 1943.61 & 0.54 & LB \\
\hline 32 & 25 & 6 & 166.67 & 8 & 1301.2 & 1164.66 & 1.12 & LDB \\
\hline 33 & 25 & 6 & 166.67 & 10 & 997.9 & 805.11 & 1.24 & LDB \\
\hline 34 & 25 & 6 & 166.67 & 12 & 789.6 & 612.06 & 1.29 & LDB \\
\hline 35 & 25 & 6 & 166.67 & 14 & 633.5 & 481.95 & 1.31 & LDB \\
\hline 36 & 25 & 8 & 125 & 6 & 2072.7 & 1966.05 & 1.05 & LDB \\
\hline 37 & 25 & 8 & 125 & 8 & 1443.68 & 1178.31 & 1.23 & LDB \\
\hline 38 & 25 & 8 & 125 & 10 & 1052.375 & 817.74 & 1.29 & LDB \\
\hline 39 & 25 & 8 & 125 & 12 & 820.98 & 623.49 & 1.32 & LDB \\
\hline 40 & 25 & 8 & 125 & 14 & 654.465 & 491.97 & 1.33 & LDB \\
\hline 41 & 25 & 10 & 100 & 6 & 2308.2 & 1985.85 & 1.16 & LDB \\
\hline 42 & 25 & 10 & 100 & 8 & 1514.48 & 1195.32 & 1.27 & LDB \\
\hline 43 & 25 & 10 & 100 & 10 & 1089.65 & 832.44 & 1.31 & LDB \\
\hline 44 & 25 & 10 & 100 & 12 & 846.21 & 636.27 & 1.33 & LDB \\
\hline 45 & 25 & 10 & 100 & 14 & 673.365 & 503.07 & 1.34 & LTB \\
\hline 46 & 30 & 6 & 166.67 & 6 & 1073.16 & 2285.25 & 0.47 & LB \\
\hline 47 & 30 & 6 & 166.67 & 8 & 1367.5 & 1452.03 & 0.94 & LB \\
\hline 48 & 30 & 6 & 166.67 & 10 & 1257.075 & 1017.54 & 1.24 & LDB \\
\hline 49 & 30 & 6 & 166.67 & 12 & 1011 & 782.91 & 1.29 & LDB \\
\hline 50 & 30 & 6 & 166.67 & 14 & 822.115 & 624.03 & 1.32 & LDB \\
\hline 51 & 30 & 8 & 125 & 6 & 2446.5 & 2414.22 & 1.01 & LDB \\
\hline 52 & 30 & 8 & 125 & 8 & 1795.46 & 1467.3 & 1.22 & LDB \\
\hline 53 & 30 & 8 & 125 & 10 & 1331.15 & 1032.75 & 1.29 & LDB \\
\hline 54 & 30 & 8 & 125 & 12 & 1051.92 & 797.4 & 1.32 & LDB \\
\hline 55 & 30 & 8 & 125 & 14 & 849.065 & 637.2 & 1.33 & LDB \\
\hline 56 & 30 & 10 & 100 & 6 & 2818.8 & 2435.49 & 1.16 & LDB \\
\hline 57 & 30 & 10 & 100 & 8 & 1886.08 & 1486.92 & 1.27 & LDB \\
\hline 58 & 30 & 10 & 100 & 10 & 1376.4 & 1050.27 & 1.31 & LDB \\
\hline 59 & 30 & 10 & 100 & 12 & 1081.89 & 812.76 & 1.33 & LDB \\
\hline 60 & 30 & 10 & 100 & 14 & 871.115 & 650.43 & 1.34 & LTB \\
\hline
\end{tabular}

\subsection{EFFECT OF WEB PLATE SLENDERNESS $\left(h_{w} / t_{w}\right)$}

\section{A. Non-compact sections}

The effect of web plate slenderness $\left(h_{w} / t_{w}\right)$ is discussed herein; see Fig. 9-a. Herein, as well, it is obvious that decreasing in the slenderness of web plate $\left(h_{w} / t_{w}\right)$ and the other dimensions are kept constant, where the section dimension was ( $b_{f}=250 \mathrm{~mm}, t_{f}=18 \mathrm{~mm}$ and $h_{w}=1000 \mathrm{~mm}$ ) leads to increase of $M_{c r, F E}$ with small value. Figure 9-b also shows an increase of length along with decrease in web plate slenderness ratio affected the value of $\left(M_{c r, F E, c}\right)$ by relatively little increase. It is obvious from Fig. 9-b, due to decrease in $h_{w} / t_{w}$, there was an small increase in $M_{c r, F E, c}$ values for all lengths except at $6 \mathrm{~m}$ length. The rate of increase is significant as a result of the mode of buckling was LB.

\section{B. 10.2 Compact sections}

Fig. 10-a explains the relationship between $M_{c r, F E}$ and the web plate slenderness ratio. The web plate slenderness was variable and the other dimensions are constant. The section used is compact, whereas $\left(b_{f}=250 \mathrm{~mm}, t_{f}=25 \mathrm{~mm}\right.$ and $h_{w}$ $=1000 \mathrm{~mm}$ ). From Fig. 10-a and Fig. 10-b It is clear that increasing in $\left(h_{w} / t_{w}\right)$ lead to decrease in both of $M_{c r, F E}$ and $M_{c r, F E, c}$ by a small percentage and increasing in the unbraced length also leads to decrease in $M_{c r, F E}$ and $M_{c r, F E, c}$. From Fig. 10-a and Fig. 10-b. It is clear that, the inclination of the lengths 
are the same. Except for the length of $6 \mathrm{~m}$, there is a difference in tendency from the rest of the lengths as shown in Fig. 10-a. This can be explained by the difference in buckling mode was LB as shown in Table 6. It is obvious that from Fig. 9 and Fig. 10 , decreasing in the flange thickness $t_{f}$ leading to decrease in $M_{c r, F E}$ and $M_{c r, F E, c}$.

(a)

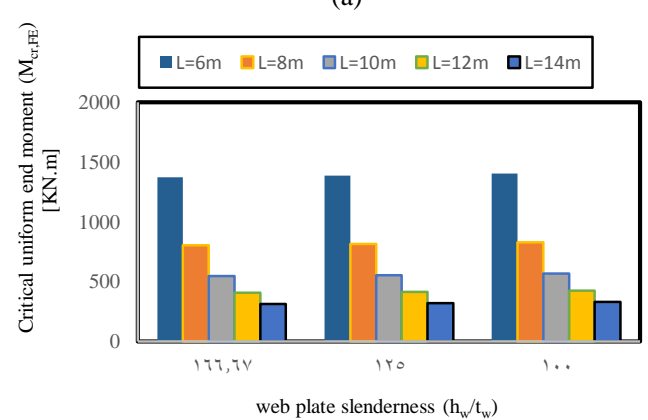

(b)

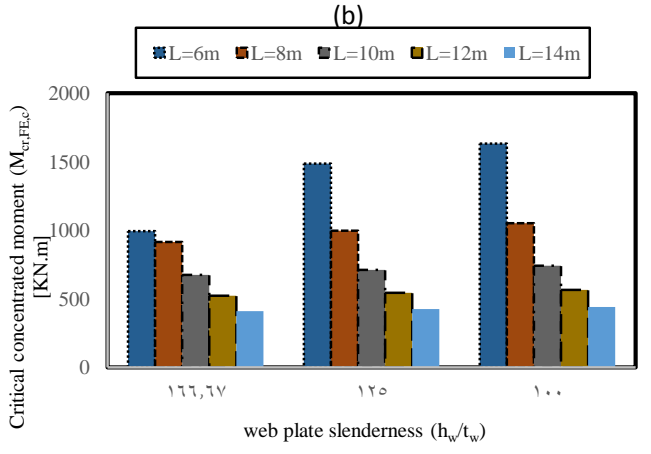

Figure 9. Effect of web plate slenderness; (a) $M_{c r, F E}$ and (b) $M_{c r, F E, c}$.
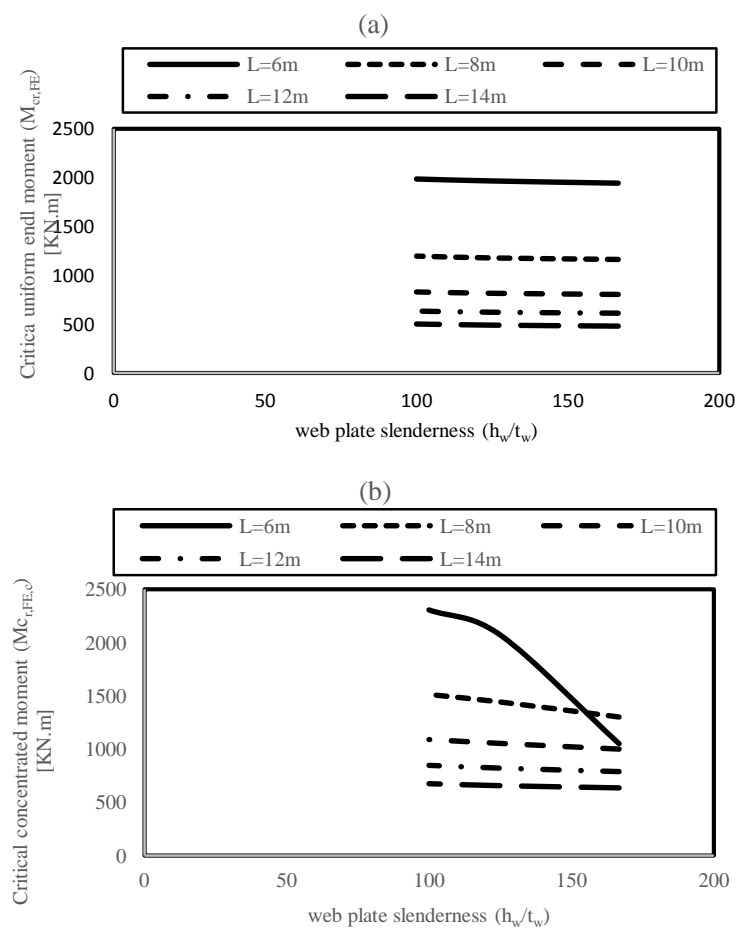

Figure 10. Effect of web plate slenderness on; (a) $M_{c r, F E}$ and (b) $M_{c r, F E, c}$.

\subsection{EFFECT OF FLANGE THICKNESS $\left(\boldsymbol{t}_{\boldsymbol{f}}\right)$}

Fig. 11 explained the relationship between flange thickness on horizontal axis and $M_{c r, F E}$ on vertical axis, whereas flange thickness was variable and rest of parameters were constant. It is clear that the increase in $t_{f}$ leads to increasing in $M_{c r, F E}$ and $M_{c r, F E, c}$ values for $h_{w} / t_{w}=166.67,125$, and 100 as shown in Fig. 11 and 12 respectively. These figures also explained the increasing in length of girders leads to decrease in $M_{c r, F E}$ and $M_{c r, F E, c}$ as previously mentioned in the effect of unbraced length paragraph. From Fig. 11 and Fig. 12, The paths of curves have almost the same inclination because the girders have the same buckling mode as LDB. Except Fig. 12-a, at $30 \mathrm{~mm}$ flange thickness, $6 \mathrm{~mm}$ web thickness and $(6,8 \mathrm{~m})$ unbraced length, failure mode was LB. As a result type of buckling mode, the curve of $(6,8 \mathrm{~m})$ unbraced length was different on the rest of other lengths.
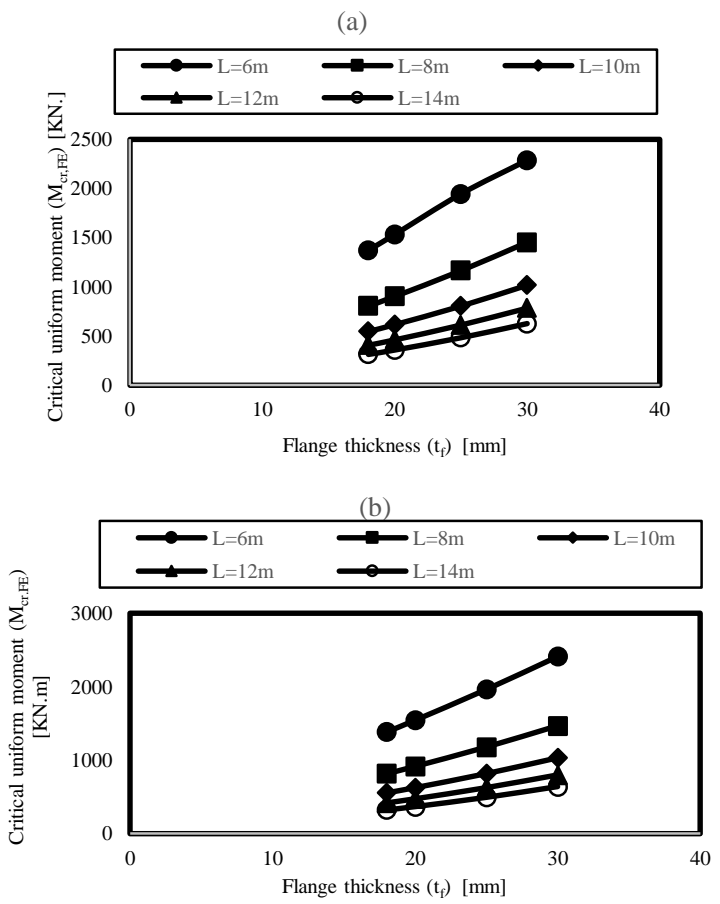

(c)

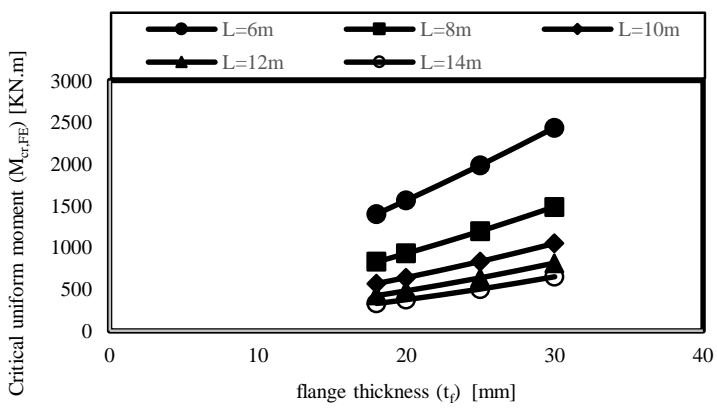

Figure 11. Effect of flange thickness on $M_{c r, F E}$; (a) $h_{w} / t_{w}=166.67$, (b) $h_{w} / t_{w}=125$, (c) $h_{w} / t_{w}=100$. 
(a)

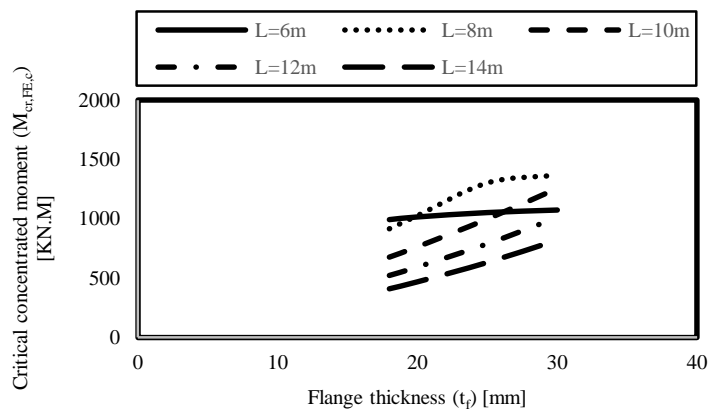

(b)

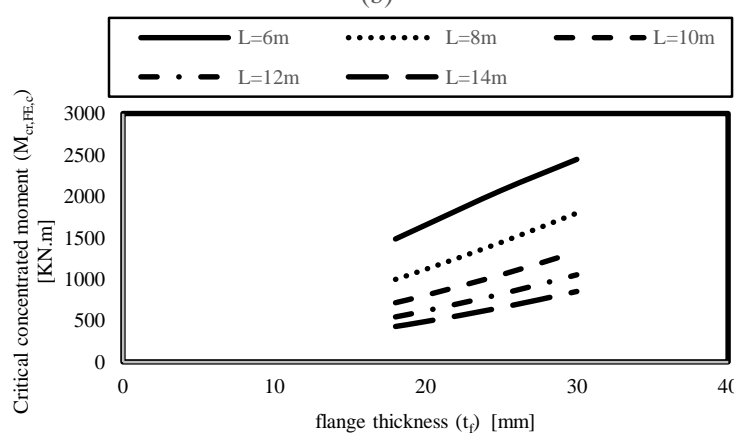

(c)

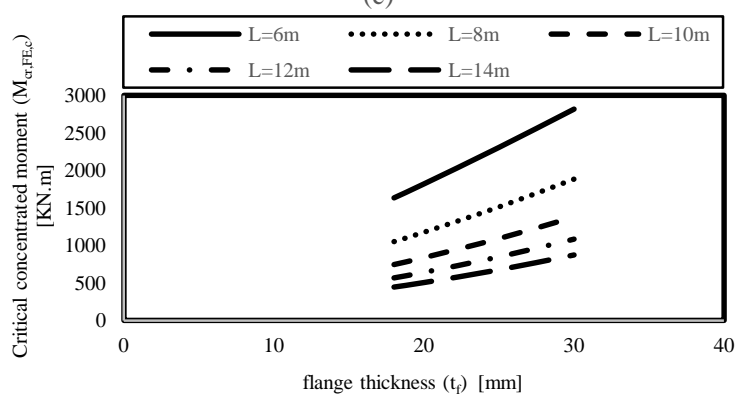

Figure 12. Effect of flange thickness on $M_{c r, F E, c} ;$ (a) $h_{w} / t_{w}=166.67$, (b) $h_{w} / t_{w}=125$, (c) $h_{w} / t_{w}=100$.

\subsection{THE $\boldsymbol{C}_{\boldsymbol{b}}$ COEFFICIENT FOR LATERAL DISTORTIONAL BUCKLING OF IPGS}

The previous results indicate that the $C_{b}$ coefficient of IPGs, which had LDB mode, may have a different value from $C_{b}$ value of LTB which equal 1.35.Table 7 explained $C_{b}$ and $\lambda$ values for specimens which failure mode of it is LDB.

From Table 8 , the limits of $\lambda$ ranges from 90 to 221 as previously mentioned. Due to the accuracy of the $C_{b}$ value of LDB, for this it was necessary to divide $\lambda$ into three parts. Table 8 explained $\lambda$ ranges and $C_{b}$ values of its ranges.

From Table 8 , it is clear that the average and standard deviation value of $\lambda$ limits (90:124) iare1.13 and 0.06 respectively. For $\lambda$ limits $(125: 175)$, the mean value and standard deviation of $C_{b}$ are 1.27 and 0.03 respectively. As for $\lambda$ limits (176:221), the mean value and standard deviation of $C_{b}$ are 1.32 and 0.02 respectively.

TABLE 8

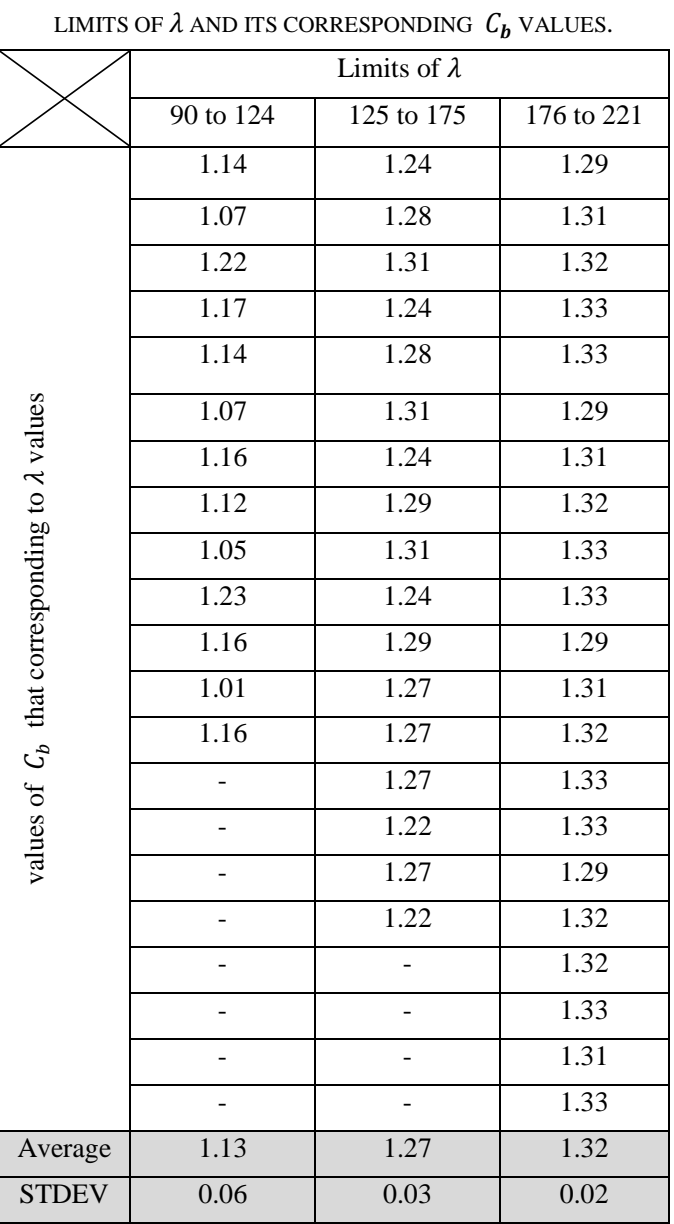

\section{CONCLUSIONS}

The linear elastic lateral-distortional buckling of IPGs under moment gradient was studied by means of the finite element method. The main aim was to investigate the effects of unbraced length, web plate slenderness and the flange thickness on the $C_{b}, M_{c r, F E}, M_{c r, F E, c}$ and buckling modes. It was found that the $C_{b}$ factors increase with increasing in unbraced length, web thickness and the flange thickness. The same is for $M_{c r, F E}, M_{c r, F E, c}$ except in the case of increasing the unbraced length the both of $M_{c r, F E}$ and $M_{c r, F E, c}$ decrease. As for the buckling mode, we notice that the increase in unbraced length, web thickness and flange thickness leading to LTB mode. In medium unbraced lengths, the buckling mode is LDB. In few cases such as decreasing in web thickness and flange thickness, the buckling mode is LB. As a result of parametric study, the mean value and standard deviation of $C_{b}$ for LDB mode are 1.13 and 0.06 respectively for $\lambda$ limits $(90: 124)$. For $\lambda$ limits (125:175), the mean value and standard deviation of $C_{b}$ are 1.27 and 0.03 respectively. As for $\lambda$ limits (176:221), the mean value and standard deviation of $C_{b}$ are 1.32 and 0.02 respectively. 
TABLE (7)

VALUES OF $C_{b}$ FOR SPECIMENS WHICH BUCKLING MODE OF IT IS LDB

\begin{tabular}{|c|c|c|c|c|c|c|c|}
\hline Groups & Specimens No. & $C_{b}$ & $\lambda$ & Groups & Specimens No. & $C_{b}$ & $\lambda$ \\
\hline \multirow{4}{*}{ 言 } & 2 & 1.14 & 122.55 & \multirow{4}{*}{ ڤ̊ } & 32 & 1.12 & 119.39 \\
\hline & 3 & 1.24 & 153.19 & & 33 & 1.24 & 149.24 \\
\hline & 4 & 1.29 & 183.83 & & 34 & 1.29 & 179.08 \\
\hline & 5 & 1.31 & 214.46 & & 35 & 1.31 & 208.93 \\
\hline \multirow{5}{*}{ 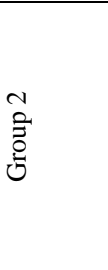 } & 6 & 1.07 & 94.66 & \multirow{5}{*}{$\begin{array}{l}\infty \\
0 \\
0 \\
0\end{array}$} & 36 & 1.05 & 91.58 \\
\hline & 7 & 1.22 & 126.21 & & 37 & 1.23 & 122.10 \\
\hline & 8 & 1.28 & 157.76 & & 38 & 1.29 & 152.63 \\
\hline & 9 & 1.32 & 189.31 & & 39 & 1.32 & 183.16 \\
\hline & 10 & 1.33 & 220.87 & & 40 & 1.33 & 213.68 \\
\hline \multirow{4}{*}{ 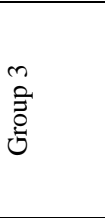 } & 11 & 1.17 & 97.32 & \multirow{4}{*}{$\begin{array}{l}\hat{0} \\
\hat{\Xi}\end{array}$} & 41 & 1.16 & 93.57 \\
\hline & 12 & 1.27 & 129.76 & & 42 & 1.27 & 124.76 \\
\hline & 13 & 1.31 & 162.21 & & 43 & 1.31 & 155.95 \\
\hline & 14 & 1.33 & 194.65 & & 44 & 1.33 & 187.14 \\
\hline \multirow{4}{*}{ 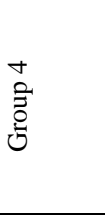 } & 17 & 1.14 & 121.43 & \multirow{3}{*}{$\begin{array}{l}0 \\
\cong \\
0 \\
0 \\
0\end{array}$} & 48 & 1.24 & 147.51 \\
\hline & 18 & 1.24 & 151.79 & & 49 & 1.29 & 177.01 \\
\hline & 19 & 1.29 & 182.15 & & 50 & 1.32 & 206.52 \\
\hline & 20 & 1.31 & 212.50 & \multirow{5}{*}{$\begin{array}{l}= \\
\cong \\
0 \\
0\end{array}$} & 51 & 1.01 & 90.23 \\
\hline \multirow{5}{*}{ 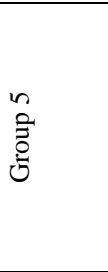 } & 21 & 1.07 & 93.57 & & 52 & 1.22 & 120.30 \\
\hline & 22 & 1.22 & 124.76 & & 53 & 1.29 & 150.38 \\
\hline & 23 & 1.28 & 155.95 & & 54 & 1.32 & 180.45 \\
\hline & 24 & 1.32 & 187.14 & & 55 & 1.33 & 210.53 \\
\hline & 25 & 1.33 & 218.33 & \multirow{4}{*}{ 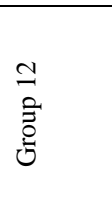 } & 56 & 1.16 & 122.55 \\
\hline \multirow{4}{*}{ 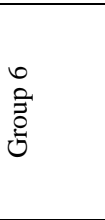 } & 26 & 1.16 & 96.00 & & 57 & 1.27 & 153.19 \\
\hline & 27 & 1.27 & 128.00 & & 58 & 1.31 & 183.83 \\
\hline & 28 & 1.31 & 160.00 & & 59 & 1.33 & 214.46 \\
\hline & 29 & 1.33 & 192.00 & & & & \\
\hline
\end{tabular}

\section{REFERENCES}

[1] Hancock GJ, Bradford MA, Trahair NS. "Web distortion and flexuraltorsional buckling". J Struct Div ASCE 1980;106(ST7):1557-71.

[2] Bradford MA, Trahair NS. "Distortional buckling of I-beams". J Struct DivASCE 1981;107(ST2):355-70.

[3] Roberts TM, Jhita PS. "Lateral, local and distortional buckling of I-beams". Thin-WalledStruct 1983;1:289-308.

[4] Bradford MA. "Distortional buckling of monosymmetric I-section beams".J Construct Steel Res 1985;5:123-36.

[5] Bradford MA. "Inelastic distortional buckling of I-beams". Comput Struct 1986;24:923-33.

[6] Bradford MA. "Lateral-distortional buckling of Tee-section beams". Thin Walled Struct 1990;10:13-30

[7] Bradford MA. "Lateral-distortional buckling of I-section members".J Construct Steel Res 1992;23:97-116.
[8] Hughes O, Ma M. "Lateral-distortional buckling of monosymmetricbeams under point load”. J Struct Mech ASCE 1996;122(10):1022-9.

[9] Ma M, Hughes O. "Lateral-distortional buckling of monosymmetric Ibeams under distributed vertical load". Thin Walled Struct 1996;26(2):12345 .

[10] Avik samanta, Ashwini kumar. "Distortional buckling in monosymmetric I-beams" Thin-walled structures 44 (2006) 51-56

[11] Tadeh Zirakian. "Elastic distortional buckling of doubly symmetric Ishapedflexural members with slender webs" Thin-Walled Structures 46 (2008) 466-475.

[12] Ilker Kalkan, Alper Buyukkaragoz. "A numerical and analytical study on distortional buckling of doubly-symmetric steel I-beams" Journal of Constructional Steel Research 70 (2012) 289-297.

[13] Song, Yuan. "Combined web distortional and lateral-torsional buckling of partially restrained I-section beams" International journal of mechanical sciences131-132 (2017) 107-112. 
[14] ABAQUS Standard User's Manual, Hibbitt, Karlsson and Sorensen, Inc, Vol. 1, 2 and 3, Version 6.6, USA, 2007.

[15] M.F. Hassanein, N. Silvestre. "Flexural behavior of lean duplex stainless steel girders with slender unstiffened webs" J Struct Eng 85 (2013) 12-23.

[16] M.F. Hassanein, O.F .Kharoob. "Flexural strength of hollow tubular flange plate girders with slender stiffened webs under mid-span concentrated loads" Thin-Walled Structures 69(2013)18-28.

[17] M.F. Hassanein n, O.F. Kharoob and A.M. ElHadidy "Lateral-torsional buckling of hollow tubular flange plate girders with slender stiffened webs". Thin-Walled Structures 65 (2013) 49-61.

[18] N. Saliba, L. Gardner "Cross section stability of lean duplex stainless steel welded I-sections". Journal of constructional steel research 80(2013) 114.

[19] Tadeh Zirakian, "Elastic distortional buckling of doubly symmetric Ishaped flexural members with slender webs", Thin-walled structures 46 (2008) 466-475.

[20] Ilker Kalkan, Alper, “ A numerical and analytical study on distortional buckling of doubly-symmetric steel I-beams", Journal of Constructional Steel Research, 70 (2012) 289-297.

[21] AA Alkawas, MF Hassanein, M Elchalakani. "Lateral- torsional buckling strength and behavior of high-strength steel corrugated web girders for bridge construction", Thin-walled structures 62 (2018) 578-587
[22] JJ Yan, MT Chen, WM Quach, M Yan, B Young "Mechanical properties and cross-sectional behavior of additively manufactured high-strength steel tubular sections", Thin-walled structures 72 (2019) 354-573.

[23] Pi YL, Trahair NS. "Distortion and warping at beam supports". ASCE J Struct Eng2000;126:1279-87.

[24] AISC, "Load and resistance factor design specification, for structural steel buildings". Chicago: American Institute of Steel Construction; 1999.

[25] Euro code3, "Design of steel structures" - part 1.1: general rules and rules for buildings, ENV 1993-1-1, CEN; 2004

[26] AISC, "Load and Resistance Factor Design Specification, for Structural Steel Buildings". Chicago: American Institute of Steel Construction; 2010

[27] Dong J, Sause R. "Flexural strength of tubular flange girders". Journal of Constructional Steel Research 2009; 65: 622-30.

[28] Akay HV, Johnson CP, Will KM. "Lateral and local buckling of beams and frames". Journal of the Structural Division, ASCE 1977; 103(3):1821-32.

[29] White DW, Jung S. "Effect of web distortion on the buckling strength of non-composite discretely braced steel I-section members". Engineering Structures 2007; 29:1872-88.

[30] Nguyen CT, Moon J, Le VN, Lee H. "Lateral-torsional buckling of Igirders with discrete torsional bracings". Journal of Constructional Steel Research 2010;66:170-7. 